\title{
edmetic
}

Revista de Educación Mediática y TIC

Aportes de la televisión universitaria a las industrias culturales y creativas en Iberoamérica

Contributions of university television cultural and creative industries in Latin America

Fecha de recepción: 21/07/2014

Fecha de revisión: 18/09/2014

Fecha de aceptación: 20/01/2015 


\section{Aportes de la televisión universitaria a las industrias culturales y creativas en Iberoamérica $^{1}$ \\ Contributions of university television cultural and creative industries in Latin America}

\section{Julio Cabero Almenara²}

\section{Resumen:}

La televisión está sufriendo en los últimos tiempos una serie de transformaciones significativas, como consecuencia de la tendencia de los usuarios a deslocalizarla de los escenarios donde tradicionalmente se observaba y a su observación a través de múltiples pantallas. Todo ello como consecuencia de la situación "trasnmedia" en la cual nos vemos inmerso. Y en esta situación se ve inmersa la televisión universitaria, televisión que frente a la comercial se encuentra en una buena situación para investigar en nuevos lenguajes y formatos, favorecer la creación de los proconsumidores, y facilitar la alfabetización mediática de la ciudadanía. Para finalizar, en el artículo se analizan las posibilidades que la televisión universitaria ofrece a las industrias culturales, que se analizan desde diferentes perspectivas: adquisición de productos audiovisuales, la formación de profesionales, la investigación en nuevos formatos, lenguajes y estéticas, y la incorporación al universo mediático televisivo de nuevos medios y recursos.

\section{Palabras claves:}

Televisión, Televisión Universitaria, Industrias Culturales, Nuevos lenguajes y formatos televisivos.

\section{Abstract:}

Television is suffering in recent times a number of significant changes as a result of the tendency of users to delocalise scenarios where traditionally observed

\footnotetext{
1 Este artículo recoge la conferencia impartida por el autor en el "6 Foro Internacional de Televisión TVMorforsis", realizado los días 27 y 28 de mayo del 2014 en Bogotá (Colombia). 
and observation across multiple screens. All this as a result of the situation "trasnmedia" in which we are immersed. And in this situation is thrown university television, television versus commercial is in a good position to investigate new languages and formats, encourage the creation of proconsumidores, and facilitate media literacy of citizens. Finally, the article explores the potential television university offers cultural industries, which are analyzed from different perspectives are discussed: acquisition of audiovisual products, professional training, research in new formats, languages and aesthetics, and the incorporation the television media universe of new media and resources.

\section{Keywords:}

Television, University Television, Cultural Industries, New Languages and television formats. 


\section{1.- Unas referencias iniciales}

La sociedad del conocimiento en la cual nos vemos inmersos, viene caracterizada por diferentes hechos, entre los cuales se encuentran su tendencia hacia la globalización, la transformación del concepto de espacio y tiempo, la rapidez en la cual la información es puesta a nuestra disposición, el ser una sociedad caracterizada por el "aprender a aprender", y el ser una sociedad compleja y dinámica frente a los momentos tranquilos en los cuales se desarrollaba la sociedad postindustrial. En definitiva, como apuntó Bauman (2007) en su momento, el que vivimos "en tiempos líquidos", donde nada es seguro, tranquilo y duradero; sino que todo se ve transformado con tal dinamismo, que nos hace estar en un estado de cambio constante, donde todo es instantáneo y donde posiblemente una de las teorías que nos sirvan para explicar nuestra situación actual sea la teoría del caos.

Sin lugar a dudas, en esta situación las Tecnologías de la Información y Comunicación han tenido una fuerte responsabilidad, de manera que frente a momentos anteriores, en la actualidad vivimos en una galaxia mediática como no había ocurrido en otros momentos históricos anteriores. Galaxia tecnológica que se aproxima al terreno educativo con una diversidad de forma y posibilidades que hasta hace poco tiempo no eran imaginables, ni se podía pensar ni soñar. Y los bordes de esta galaxia son claramente difusos, como podemos inferir a partir de los Informes Horizon (García, Peña-López, Johnson, Smith, Levine, y Haywood, 2010; Durall, Gros, Maina, Johnson, y Adams, 2012), que específicamente se han elaborado para Iberoamérica, donde se apuntan tecnologías que a corto y medio plazo empezarán a llamar a las puertas de nuestras instituciones educativas, como son los entornos personales de aprendizaje, la web semántica, la realidad aumentada, la computación en nube, los dispositivos móviles, o los medios sociales. Todo ello posiblemente propiciado por la gran significación que ha adquirido Internet, por un lado, y las web 2.0, por otro.

Pues bien, en esta transformación la televisión no es un medio a olvidar. 
La historia de la comunicación ha puesto claros ejemplos de que la aparición de una nueva tecnología de la información no nos lleva a un desplazamiento completo de la precedente, salvo en el caso de que se trate de una tecnología de sustitución. Así la radio, no mató a la prensa, el cine no mató al teatro, y la televisión ni mató en su momento al cine ni a la radio. Lo que si ocurre es que se da una reubicación de las funciones que desempeñan los medios y los dispositivos con que se cuentan para cubrir esas funciones. Y esto es especialmente importante en el caso de la televisión universitaria, como posteriormente veremos.

Y de nuevo la historia se repite, y toda la galaxia de Internet, no han hecho desaparecer al medio televisivo, sino que lo está reubicando en el escenario comunicativo.

Desde una perspectiva que algunos pudieran considerar como un poco simplista, y posiblemente lleven razón, creo que la televisión ha pasado por dos grandes momentos de desarrollo; uno vino, por la aparición del color, y otro, por la digitalización de la señal. Esta última, nos está trayendo nuevas formas de usarla, nuevas formas de explotarla y nuevas formas de extenderla; lo que nos está llevando a redefinirla como medio de comunicación.

En el año 2005, me pidieron en un congreso que giraba en torno a la temática de la calidad en la televisión, que impartiera una de sus conferencias, y la denominé: ¿Pero sigue existiendo la televisión en un Universo Global de comunicación? (Cabero, 2005). Si mal no recuerdo, eran los momentos en los que Internet comenzaba a presentarse como la tecnología verdaderamente transformadora y disruptiva del universo comunicativo. Y allí señalé, que los cambios que se estaban produciendo en éste universo, se debían a una serie de apariciones, que posiblemente estaban todas relacionadas, y que deberíamos comprenderlos si queríamos entender qué estaba ocurriendo y qué podría ocurrir con la televisión, estas apariciones eran:

- La aparición de nuevas tecnologías en el universo mediático. 
- De nuevos usuarios.

- De nuevos tipos de usuarios.

- Y de nuevas modalidades de utilización de las tecnologías de la información y comunicación.

Y también que estas transformaciones nos estaban llevando no a la desaparición de la televisión, sino a una nueva forma de uso, de convergencia con otras tecnologías, y de convergencias de pantallas. De todas formas, no podemos negar que en los momentos actuales la televisión ha perdido terreno frente a otros medios en los cuales el usuario tiene mayor protagonismo y dominio del contenido. Un estudio llevado a por la "Asociación de Investigación en Medios de Comunicación" realizado en el año 2010 en España, puso de manifiesto que el $68 \%$ de los españoles dedicaban menos tiempo a ver televisión que a navegar por Internet. Y que uno de cada tres encuestados, reconoció que había visto la televisión a través de Internet; creo que no me equivoco al señalar que el fuerte impulso que en los últimos tiempos han adquirido las tablet y la conexión wifi, están repercutiendo para que más usuario establezcan la interacción con los contenidos audiovisuales a través de la "segunda pantalla" (González y López, 2011).

Creo que es importante dedicar unos instantes a realizar una serie de reflexiones sobre alguno de los puntos que he comentado, pues ellos nos van a servir posteriormente para explicar que está pasando con la televisión universitaria, para analizar las posibilidades que nos ofrece en el nuevo terreno comunicativo y mediático que se nos está presentando, y algunas claves de por dónde debe dirigirse la misma.

Una de las primeras referencias que me gustaría realizar, es que las formas de ver los programas de televisión están cambiando, sobre toda en las nuevas generaciones. Cada vez la forma de ver e interaccionar con los contenidos televisivos se ve condicionada más por dos aspectos: a) su observación en la denominada "segunda pantalla" y b) su observación en la televisión móvil. 
La observación de los programas, cada vez se centra menos en un tiempo y espacio determinando, y se abre más a nuevos escenarios, ampliando y deslocalizando los lugares y las tecnologías con las cuales podemos acceder al mensaje televisivo. Y ello ofrecerá, sin lugar a dudas, grandes posibilidades para la televisión universitaria, y establecerá fuertes diferencias con la televisión comercial.

Estas nuevas formas de acceder a los contenidos televisivos, sobre todo a través de Internet, nos ofrecerá un amplio abanico de posibilidades para:

- Ofrecer una gran cantidad de contenidos.

- No tener límites geográficos.

- Facilitar la distribución de contenidos.

- Permitir un mayor control de las audiencias.

- Tener menos costo para poner en acción los proyectos televisivos.

- Y facilitar nuevas formas de participación del televidente.

Sin lugar a dudas, podríamos señalar que la incorporación de la red al mundo de la televisión, ha ayudado a que pasemos de concebirla como un medio "frío", utilizando la terminología de Mcluhan, a uno "caliente"; es decir, de un medio donde uno es solamente observador de mensajes, a otro que nos permite participar a diferentes niveles (aportación de contenidos, intervención, en los programas, y seguidor o evaluador de los mismos a través de diferentes herramientas de la web 2.0, como los blog o las redes sociales.

Pero si ha cambiado la tecnología de interacción con los contenidos, tampoco nos podemos olvidar que progresivamente van cambiando las características de los espectadores. Aunque no estoy de acuerdo con esa clasificación tan radical que se ha realizado entre "nativos" y "emigrantes" digitales, y no lo estoy por diferentes motivos: a) los desarrollos tecnológicos los están realizando más los clasificados como "emigrantes" que los "nativos", b) la diferenciación no se puede hacer tomando como elemento únicamente la edad, sino que más bien, ya empiezan a tomarse otros parámetros, como por 
ejemplo las formas en las cuales interaccionamos y construimos los mensajes con las tecnologías, y aquí de nuevo los "emigrantes" hacen usos más profundos y más complejos que los "nativos", y c) que muchas veces hemos establecido categorías para indicar algo que muchas veces no sabemos lo que son.

Lo que no podemos dejar de reconocer, es que hay una diferencia clara en cuanto a cómo acceden, a las tecnologías unos y otros, y las estructuras cognitivas que poseen como consecuencia de la interacción que establecen con diferentes tecnologías y sistemas simbólicos; posiblemente los "nativos" sean más multitareas, están acostumbrados a trabajar con una sobrecarga de información, tienden a ser interlocutores activos, y se presentan como prosumidores. Aunque también presentan dificultades en las habilidades cognitivas de la atención y la concentración (Carr, 2011; Goleman, 2013).

Lo apuntado me lleva a señalar que la diferencia no sea tan amplia en la brecha digital, pero si cerebral, al movilizar estructuras cognitivas diferentes, para el procesamiento de la información, y al tener en consecuencia actitudes diferentes para interaccionar cognitivamente de manera distintas con tecnologías específicas y con formatos concretos.

De estos "nativos", podemos decir que no están contentos con un modelo de televisión unidireccional, o mejor dicho que persiguen acercarse a la misma desde una óptica diferente a como la hemos realizado tradicionalmente. Lo que nos lleva a una reflexión, que sobre todo nos va a servir cuando hablemos de las posibilidades que nos ofrece la televisión universitaria, y es que si el medio televisivo quiere retener a estas nuevas generaciones, tiene que buscar nuevos formatos televisivos que presenten características como las siguientes:

- Ser más interactivos.

- Más participativos.

- Colaborativos.

- Evolutivos. 
- Y con la búsqueda de la innovación permanente.

Para analizar cómo debe ser la televisión universitaria, debemos aprender de los usos que las nuevas generaciones realizan de otras tecnologías, como las de universo de la web 2.0; donde los usuarios son más creadores, actores, colaboradores y organizadores, que meros consumidores, es decir, abandonar la idea de construir medios que lleven a las personas únicamente a ser usuarios y receptores pasivos de la tecnología; como ya he señalado las nuevas generaciones tienden a ser más prosumidores que consumidores de mensajes audiovisuales y tienen a observar los contenidos audiovisuales que se presentan por ellos a través de múltiples pantallas.

Realizados estos comentarios, previos pasaré a abordar el tema de la televisión universitaria.

\section{2.- La televisión universitaria}

Podríamos comenzar nuestro análisis intentando ofrecer una definición de televisión universitaria, y en este sentido ha habido diversas, como la que en su momento ofreció la "Asociación Brasileña de Televisión Universitaria", que la concreta en sus estatutos, como aquella televisión dirigida estrictamente a la promoción de la educación, la cultura y la ciudadanía, y que puede funcionar de manera diversas: utilizando Internet, televisión por cable, satélite, o televisión abierta.

De todas formas creo que más interesante que el formalizar una definición, sea el establecer algunas de las características que desde mi punto de vista pueden ser definitorias de la televisión universitaria y que nos permiten diferenciarla de otros tipos de televisión. Y posiblemente la primera, sea el indicar que es una televisión que orgánicamente depende de alguna forma, de la estructura orgánica de una Universidad, y desarrolla su estrategia de programación, atendiendo a criterios no comerciales, pudiendo permitir en cierta medida la participación de los profesores y los estudiantes. Aunque este aspecto lo matizaré posteriormente. 
Identificado este carácter institucional, es cuándo podremos señalar que hablar de televisión en la Universidad es hablar de:

- Una producción realizada de manera que respecte las diferencias, y por tanto que sea plural.

- Imaginativa.

- Creativa.

- Educadora.

- Con una fuerte misión cultural.

- Y con una misión hacia la alfabetización mediática.

Hablar de televisión universitaria es contemplar de cara al desarrollo de la programación, que existen diferentes tipos de programas que pueden interesar a la audiencia, y que lleva a la hora de la organización y diseño de su programación, a no olvidarnos que su territorio de acción son los programas de carácter:

- Didácticos

- Documentales

- Culturales.

- Científicos.

- E institucionales.

Como podemos ir imaginándonos, los roles y funciones que debe cumplir la televisión universitaria son, y deben ser, claramente diferentes a la televisión comercial; por ello su eficacia debe medirse por otros aspectos y variables, y no únicamente por el volumen de audiencias, entre estas variables podemos hablar de la formación cultural y democrática de la ciudadanía.

Es por tanto hablar de una televisión que persigue defender, y defender en mayúscula, LA CULTURA, LA EDUCACIÓN Y LA CIENCIA; es hablar de una televisión que tiende a moverse por la vía democrática de la participación, entendiéndola como un espacio mediático en el cual pueden participar diferentes actores, que van desde los responsables políticos e institucionales de la Universidad, hasta los profesores, estudiantes y el personal de administración 
y servicios de la misma. Sin que ello suponga, el olvidarnos de otros colectivos, ya que hacer una televisión universitaria no significa centrarnos exclusivamente en el personal académico.

La televisión universitaria implica una tipología de televisión que se convierte en un cauce privilegiado de expresión de las inquietudes y proyectos de la comunidad educativa; por tanto, es un elemento que puede ser significativo para dinamizar la vida académica, social y cultural de la Universidad; puede por tanto ser un elemento clave de transmisión de la cultura y proyección social y académica de la Universidad.

Desde mi punto de vista, si hay una característica claramente definitoria de la televisión universitaria, es que es un modelo de televisión que debe ir claramente dirigido hacia la innovación, la experimentación, y la creación y producción de nuevos géneros, formatos y estéticas televisivos. No debe caber la menor duda que las televisiones universitarias juegan un rol muy efectivo como espacios de innovación y experimentación, ya sea en la programación, en la formación de personal, en los contenidos, o en la interactividad. Es por tanto hablar de una televisión que debe reinventarse constantemente, todo ello en beneficio de conseguir programas de televisión de calidad.

Calidad que no tienen por qué estar limitada a la televisión comercial, hay televisiones universitarias que realizan programaciones de gran calidad, como por ejemplos las mexicanas TV UNAM, Canal 11, y Canal 44, o el canal Zoom de Colombia.

Y cada vez hay más televisiones educativas y culturales en el contexto latinoamericano, en México, por ejemplo, hace 10 años solamente había dos televisoras en la actualidad existen unas 13. En Brasil hay más de 40. Y en España, fundamentalmente bajo la modalidad de difusión a través de Internet, ya empiezan casi todas las Universidades a disponer un canal. Aunque también se cuentan con otras experiencias, como la de la UNED que emite un programa semanal por la segunda cadena de televisión española, o nosotros, en la Universidad de Sevilla, que además de nuestra televisión por Internet, 
realizamos un programa para una televisión local (tv Correo) de una hora semanal.

Ahora bien, algunos de los comentarios que estoy realizando deben ser matizados si se quiere realizar una televisión en la cual sus parámetros sean de calidad no sean ínfimos, y en este caso me estoy refiriendo a parámetros de calidad comunicativa. Y lo primero que debemos señalar, es por una parte, que la divulgación no ha de suponer distorsión del rigor científico, y por otra, que divulgar no debe significar infantilizar o vulgarizar. Desde nuestro punto de vista se ha de mantener un grado de equilibro entre la vulgarización y el cientificismo. Democratizar la ciencia no es ni vulgarizarla ni únicamente divulgarla.

Un canal universitario deberá educar e informar, sin embargo eso no significa que deba transformarse en una cadena de televisión educativa a distancia, sino que más bien se deba convertir en una escenografía para atender a necesidades de un público diverso, y que contribuya a la creación de públicos críticos. Lo que estamos indicando, nos lleva a señalar con toda claridad que hablar de televisión universitaria no debe significar, pensar que el público final de destino sea exclusivamente el universitario. Sino que debe perseguir alcanzar a la globalidad de la ciudadanía.

Es cierto que la mayoría de las televisiones universitarias han comenzado como institución para la producción de materiales educativos prioritariamente en soporte vídeo y para el consumo interno de la propia Universidad. Pero este modelo ha ido evolucionando hacia otro que persigue atender a lo local, regional, nacional e internacional; y no se centra exclusivamente en lo académico, sino que tiende hacia lo cultural y educativo. En este sentido no podemos olvidarnos que Universidad más allá de conferencias y clases magistrales es una fuente inagotable de contenidos audiovisuales.

En esta televisión hay diferentes modelos de gestión, que sin lugar a dudas van a condicionar su puesta en acción y los roles que desempeñe, y al respecto básicamente podemos hablar de cuatro: 
a) Un modelo de televisión asociado a cursos de televisión, periodismo y ciencias de la comunicación de las Universidades.

b) Un modelo centrado en los gabinetes de comunicación de las Universidades.

c) Una televisión universitaria en manos de una televisión local o productora.

d) Y un modelo de desarrollo dentro de una institución autónoma, como es el caso del "Secretariado de Recursos Audiovisuales y Nuevas Tecnologías" (SAV) de la Universidad de Sevilla (http://www.sav.us.es).

Ahora bien lo que estamos hablando supone una serie de retos, sobre todo en lo referido a los formatos televisivos con los cuales deberemos trabajar. Y el primer indicador, es que la presentación y el formato que utilicemos deben ser lo suficientemente atractivos para que el espectador se sienta interesado y valore las actividades relacionadas con la educación, la cultura y la investigación, como algo cercano, significativo e interesante. Soy de los que piensan que la televisión universitaria debe tender a provocar al receptor, a través de nuevos lenguajes y formatos.

Desde mi punto de vista, para que una televisión universitaria funcione debe hacer una producción diferente a las que tradicionalmente se realizan en la televisión cultural. Y desde aquí, la televisión universitaria tiene un fuerte desafío y es la innovación en los diferentes lenguajes audiovisuales. Será por tanto, uno de los objetivos de esta televisión la de fomentar la expansión de esos nuevos lenguajes y de los nuevos modelos de comunicación a ellos asociados.

Lo comentado nos lleva a señalar que la televisión universitaria se incardina, dentro de las propias metas de la Universidad, entre las que se encuentran la de la innovación y la investigación.

En este aspecto de los formatos, una de las cuestiones a señalar es que se deben buscar nuevos formatos que capturen a los jóvenes y para ello 
puede ser interesante el trabajar con dos ideas: la de un visionado en la "múltiples pantallas" y el de que pueden participar en la producción de mensajes televisivos. Como ya señalé, las nuevas generaciones, han cambiado las formas de ver la televisión, por una parte éste ha dejado de ser un medio que es observado de forma colectiva para tender hacia lo individual, en segundo lugar, que se tiende a observar a través de los dispositivos móviles, y en tercer lugar que es uno que transciende al propio medio televisivo y se inserta en una galaxia mediática con Internet, la web 2.0 y las redes sociales.

Estas nuevas formas de observar los programas, está repercutiendo en diferentes aspectos que debemos tener en cuenta a la hora de producir programas, como son: su duración, los formatos de producción a utilizar, la búsqueda de nuevas estéticas, o el tipo de contenido a transmitir.

Desde nuestro punto de vista, hablar de televisión universitaria es hablar de coproducción y colaboración; es entender que se pueden producir programas de forma diferente a los de la televisión comercial, en donde la coproducción y la colaboración, se convierten en un elemento significativo. Con el valor añadido, de sobrepasar a la simple producción de programas y en donde la investigación, la formación y el aprendizaje se convierten en valores de cambio. Sin olvidarnos de las ventajas adicional de la reducción de los costos de producción.

Y desde esta perspectiva, nos encontramos con que la colaboración y la coproducción pueden tener diferentes visiones, que van desde la simple coproducción de materiales, a la cooperación en proyectos, hasta el establecimiento de redes estables de colaboración.

La producción conjunta la podemos entender desde diferentes perspectivas:

- Coproducción de serie de programas donde cada socio produce un programa.

- Cofinanciación, donde todas las instituciones participantes aportan recursos y es una la que los produce. 
- Y la producción mediante trabajo colaborativo, donde las instituciones se incardinadas en el proyecto e intercambian sus producciones y bancos de imagen, para llevar a cabo una producción conjunta (Salinas, 1995).

Ahora bien asumir principios de colaboración en la producción, exige y reclama que dentro de las Universidades se creen estructuras ágiles y menos burocráticas que permitan alcanzar acuerdos sin grandes dificultades.

Lo que estamos comentando nos lleva a otros aspectos significativos de las televisiones universitarias, y son las posibilidades que nos ofrecen para configurar redes de producción. Claros ejemplos de lo que hablo es la ATEl y el Canal Zoom de Colombia. El centro que yo dirijo en la Universidad de Sevilla, el "Secretariado de Recursos Audiovisuales y Nuevas Tecnologías", ha participado a nivel nacional e internacional en la coproducción de diferentes series que además de ser emitidas por televisión a través de Internet, se han emitido en abierto por televisión española.

Tal coproducción además de favorecer la elaboración de materiales de calidad, tiene la gran ventaja de extender las temáticas producidas a diferentes escenarios.

Independientemente de la coproducción, la emisión de programas de televisión a través de Internet, permite la realización de programas no tan costosos en nuevos formatos, que facilitan dar espacio a los nuevos realizadores, y que pueden ser de interés para un público especial televidente, que persigue la innovación y la creatividad.

Continuando con la problemática de los formatos, creo que no nos equivocamos al señalar que si la televisión comercial ha cambiado muy poco, y por lo general sigue en una estructura de propiciar un modelo unidireccional de comunicación. Ello no pasa con la televisión universitaria, que está propiciando la integración de tecnologías, la incorporación de nuevos canales de comunicación, y la investigación en la búsqueda de nuevos formatos televisivos. Y la participación del receptor a través de nuevos caminos de 
expresión, como pueden ser las redes sociales y la producción de documentos por parte de los espectadores. En este último caso, la televisión universitaria puede potenciar el que los usuarios se conviertan en productores de contenidos o prosumidores. Valga como ejemplo las secciones de los programas incorporados en la televisiones universitarias, donde los alumnos participan enviando videomensajes, grabados a través de diferentes dispositivos móviles. El sueño dorado de la democracia era que los ciudadanos realizaran contenidos y mensajes, está siendo alcanzado gracias a las tecnologías que últimamente están apareciendo.

Para finalizar estas referencias a la televisión universitaria, creo que es importante señalar que puede desempeñar un rol muy importante para la adquisición de la competencia de Educomunicación en los receptores potenciales, favoreciendo eso que desde ciertos sectores se ha denominado como educación mediática a lo largo de toda la vida.

Esta alfabetización mediática es más necesaria de lo que podemos creer, ya que en la sociedad del conocimiento no es suficiente con que el ciudadano posea unos elevados niveles de alfabetización en lectoescritura e impresa, sino que también debe poseer una alfabetización en el lenguaje y cultura audiovisual, en tecnologías y cultura digital, y una alfabetización informacional. Dicho en otros términos que la persona posea unos niveles de alfabetización mediática, que le permita la codificación y decodificación de mensajes que propicie la interacción con los nuevos lenguajes que se están generando a partir de los nuevos medios.

Alfabetización mediática que implica una serie de aspectos como son:

- Sentirse cómodo con todos los medio de comunicación existentes.

- Utilizar activamente los diferentes medios con que nos encontramos.

- Utilizar los medios con creatividad en un momento en el que la evolución de la tecnología va a bastante velocidad como consecuencia directa de la digitalización. 
- Comprender la economía de los medios y la diferencia entre pluralismo y la acaparación de los medios.

- Y ser conscientes de los asuntos relacionados con la propiedad intelectual (Area, Gros y Marzal, 2008; Cabero, Marín y Llorente, 2012).

En definitiva podemos decir que la televisión universitaria puede ser un elemento clave para la educación mediática y audiovisual del espectador, desde unas perspectivas activas, lúdicas y críticas.

\section{3.- Unas referencias respecto a las relaciones entre industrias culturales y televisiones universitarias.}

A la hora de especificar lo que podemos entender por industrias culturales, bien nos podemos apoyar en la concreción que en el 2009, realizó la Unesco, que las entienden como: Aquellos sectores de actividad organizada que tienen como objeto principal la producción o la reproducción, la promoción, la difusión y/o la comercialización de bienes, servicios y actividades de contenido cultural, artístico o patrimonial.

Y que presenta como características definitorias las siguientes:

- Principales características de las industrias culturales y creativas.

- Intersección entre la economía, la cultura y el derecho.

- Incorporan la creatividad como componente central de la producción.

- Contenido artístico, cultural o patrimonial.

- Bienes, servicios y actividades frecuentemente protegidas por la propiedad intelectual - derecho de autor y los derechos conexos.

- Doble naturaleza: económica (generación de riqueza y empleo) y cultural (generación de valores, sentido e identidades) Innovación y recreación.

- Demanda y comportamiento de los públicos difícil de anticipar.

En síntesis, podríamos decir que la Industria cultural se podría definir como el conjunto de empresas e instituciones cuya principal actividad 
económica es la producción de cultura con fines lucrativos.

Industrias culturales que en los últimos años han estado marcadas por una serie de hechos y de acontecimientos:

- Su progresiva desregulación del sector público.

- Su concentración en grandes grupos.

- La globalización.

- Y el asumir que suponen una fuente de desarrollo económico.

No estaría mal reconocer desde el principio que las industrias culturales son un fuerte sector dinámico de desarrollo social y económico, de forma particular de la cultura, y de forma general en la economía global de un país. Y para poner un ejemplo señalar que en Londres el $30 \%$ de la población trabajadora está relacionada directamente o indirectamente con la industria cultural, en París el 20\%, y en Barcelona se sitúa cercano al 11\%. Es decir, hablar del sector de la industria cultural es hablar de un sector significativo desde un punto de vista económico, y que tiene fuertes influencias sobre el número de empleados.

Los contenidos en las industrias culturales tienen un valor añadido, y es que al contenido, se adjunta, consciente o inconscientemente, la imagen del país. Las industrias culturales han sido claves para el conocimiento de Iberoamérica en otros contextos como el europeo. El imaginario social que se tenía de Latinoamérica en Europa en la década de los 70, se ha visto fuertemente transformado en los últimos años desde la llegada de productos culturales como la música, los libros o el cine.

Y aquí ya viene un dato que nos debe llevar a reflexionar, y es que Latinoamérica es más importadora de bienes culturales que exportadora, sin hablar de su fuerte dependencia tecnológica, lo que claramente dificulta el nacimiento de un sector audiovisual cultural.

Aunque asumiendo cierto reduccionismo, creo que podemos indicar que para comprender el negocio de la televisión, es necesario diferenciar dos grandes tipos de industrias respecto al medio sociológico que analizamos: la 
de los equipos y la referida a los contenidos audiovisuales. Sin despreciar la primera, que va a influir en la televisión universitaria en busca de nuevas tecnologías para la creación y difusión, teniendo como eje la reducción de los costos. Me parece más significativo para el análisis que voy a realizar la segunda; es decir, las relaciones entre televisiones universitarias e industrias culturales.

No debemos olvidarnos que la globalización ha influido en la extensión de una cultura y de una comunicación masiva, de manera que la cultura se ha despegado de su entorno local. Y la cultura y la comunicación se han convertido en una mercancía que ha generado una industria cultural donde la mercancía son los objetos culturales en sus diferentes formas: teatro, libro, cine o programas de televisión.

La relación entre televisiones universitarias e industrias culturales, las podemos analizar desde diferentes perspectivas:

a) La adquisición de productos audiovisuales, y por tanto la potenciación del nacimiento de una industria cultural audiovisual.

b) La formación de profesionales.

c) La investigación en nuevos formatos, lenguajes, y estéticas.

d) Y la incorporación al universo mediático televisivo de nuevos medios y recursos.

Desde los comentarios que estamos realizando creo que todos estaremos de acuerdo en que la televisión universitaria puede favorecer el desarrollo de una industrial cultural, tanto local como nacional, que aporten o produzcan dichos contenidos que puedan ser utilizados en la televisión universitaria. Pero ello debe suponer que las industrias culturales asuman las reglas del juego de los nuevos formatos y las características específicas de la televisión universitaria.

Al mismo tiempo las televisiones universitarias pueden ser buenos escenarios para la formación en el medio televisivo a las nuevas generaciones mediante la realización de prácticas, así como servir para dar la voz a los 
jóvenes realizadores, y favorecer de esta forma su impulso. En esta línea que comentamos, la televisión universitaria puede desempeñar un rol importante para la formación de expertos en comunicación y expertos en la formación de profesionales del medio televisivo. Y desde aquí las televisiones universitarias pueden servir de aliento para que las propias Universidades se conviertan en incubadoras de empresas donde profesores y alumnos se adentren, no solo en el tema de la producción audiovisual televisiva, sino también en el terreno de la elaboración de empresas culturales que puedan aportar contenidos a la televisión.

Desde esta perspectiva creo que la televisión universitaria tenemos que percibirla como un elemento de promoción de la identidad cultural, y aunque deba perseguir un alcance transnacional, en su emisión y producción, ello no debemos percibirlo como un elemento de normalización y homogenización cultural, que nos puede llevar a una Mcculturización, sino más bien a cultivar lo local y la identidad nacional, desde lo global. Recientemente ha habido en España el "VI Foro de Industrias Culturales", y una de las reivindicaciones que se ha realizado en el mismo es la reivindicación del "Hecho en Europa", ya que las cadenas de televisión europeas sistemáticamente incumplen la normativa que indica que el $51 \%$ de las emisiones deben ser de contenidos europeos. En Colombia todas las teledifusoras están obligadas a ofrecer en su parrilla, el canal educativo y cultural Zoom.

Para finalizar quisiera señalar una serie de aspectos.

a) Por una parte, que las televisiones universitarias son un excelente recurso para hacer una Universidad MEJOR, en el sentido de que sus mensajes e ideario lleguen a más personas y alcancen mayor distancia.

b) Es una vía para favorecer un reto en el cual estamos inmersos todas las universidades y es el de la internalización. Es una vía por tanto para potenciar el desarrollo de la marca específica de la 
Universidad, y de hacer que sus valores, conocimientos y culturas, se expandan fuera de los muros de las instituciones universitarias.

c) Si el futuro de la comunicación científica pasa invariablemente por Internet, y desde este punto de vista no podemos dejar de reconocer que las experiencias que se están realizando apoyan claramente la idea de que las televisiones universitarias están sirviendo para dar un fuerte desarrollo a la comunicación científica.

d) Debe evitarse la no realización de productos que no sean de calidad. A veces se prima la presencia cuantitativa a lo cualitativo. Y no debemos olvidar que bajo la televisión universitaria se encuentra la marca de la Universidad y se está transfiriendo la imagen de la institución. Como ya señalé, desde mi punto de vista lo importante en la televisión universitaria no es la lucha por las audiencias sino por la formación de la ciudadanía. La televisión universitaria debe medirse en términos sociales y culturales, no simplemente económico. En la televisión universitaria, hay un fuerte valor social añadido.

e) No olvidarnos que la digitalización de la señal, proceso en el cual se encuentran inmerso diferente países Latinoamericanos, abre nuevas posibilidades de extensión a las televisiones universitarias.

f) Y contemplar que las universidades deben enseñar a comprender lo que los espectadores hacen con la televisión. Tan importante es comprender lo que la tecnología hace con las personas, como lo que las personas hacen con la tecnología.

Por ello creo que debemos tender a que las universidades utilicen la televisión como parte de su propia estructura universitaria, como un elemento que exponga ante la sociedad las actividades que realiza, los retos que persigue, y los logros que alcanza. 


\section{Referencias bibliográficas}

AREA, M., GROS, B. Y MARZAL, M.A. (2008). Alfabetizaciones y tecnologías de la información y comunicación. Madrid: Síntesis.

BAUMAN, Z. (2007). Los retos de la educación en la modernidad líquida. Barcelona: Gedisa.

CABERO, J. (2005). ¿Pero sigue existiendo la televisión en un universo global de comunicación? Comunicar. 25, 57-62.

CABERO, J., MARÍN, V. Y LLORENTE, M.C. (2012). Desarrollar la competencia digital. Educación mediática a lo largo de toda la vida. Sevilla: Eduforma.

DURALL, E., GROS, B., MAINA, M., JOHNSON, L., Y ADAMS, S. (2012). Perspectivas tecnológicas: educación superior en Iberoamérica 2012-2017. Austin: The New Media Consortium.

GARCÍA, I., PEÑA-LÓPEZ, I., JOHNSON, L., SMITH, R., LEVINE, A., Y HAYWOOD, K. (2010). Informe Horizon. Edición iberoamericana 2010. Austin: The New Media Consortium.

GOLEMN, D. (2013). Focus. Desarrollar la atención para alcanzar la excelencia. Barcelona: Kairos.

GONZÁLEZ, P. Y LÓPEZ, N. (2011). La generación digital ante un nuevo modelo de televisión: contenidos y soportes preferidos. Anàlisi, 44, 31-48.

SALINAS, J. (1995). La producción universitaria de televisión y vídeo educativos: entre la coproducción y la cooperación. En I. Aguaded y J. Cabero (dirs). Educación y Medios de Comunicación en el contexto iberoamerican. (pp. 103-119).Huelva, Universidad Internacional de Andalucía sede Iberoamericana de la Rábida.

\section{Como citar este artículo:}

Cabero Almenara, J. (2015. Aportes de la televisión universitaria a las industrias culturales y creativas en Iberoamérica. EDMETIC, Revista de Educación Mediática y TIC, 4(2), 7-28. 